\title{
Saccharin aversion produced by reversible functional cortical ablation
}

\author{
NELSON L. FREEDMAN and ROGER WARD \\ Queen's University at Kingston, Kingston, Ontario, Canada
}

\begin{abstract}
Rats exposed to novel sodium saccharin solution followed by a single 1-h treatment of KCl-induced spreading cortical depression (CSD) show a long-lasting conditioned aversion to subsequent presentations of saccharin. Control rats treated with isotonic Ringer's solution do not show this effect, nor do rats treated with CSD but not exposed to saccharin. Therefore, these results cannot be attributed to known effects of CSD on hunger, memory, or general debilitation. Results are interpreted in terms of prevalent theory of taste aversion and recovery from lateral hypothalamic and cortical insult.
\end{abstract}

Current investigations have emphasized the role of forebrain in addition to hypothalamic mechanisms in the control of feeding (e.g., Freedman, Ferguson, \& Wilson, 1972). Teitelbaum and Cytawa (1965) had earlier demonstrated that cortical spreading depression (CSD), for example, would reinstate aphagia and adipsia in rats with lateral hypothalamic (LH) lesions. Thus, normal cortical activity may act to facilitate and maintain recovery by enhancing the activity of depressed, but intact, hypothalamic tissue adjacent to the lesion.

Several alternative views of recovery of feeding following $\mathrm{LH}$ lesions have emerged. Teitelbaum, Cheng, and Rozin (1969) suggest that such recovery of feeding parallels the development of feeding in newborn animals. It follows that recovery from LH damage involves reencephalization resembling that occurring from birth. A second possibility, consistent with the first, is that recovery involves a relearning process. Balinská, Buresová, and Fifková (1967) demonstrate that the reinstatement of aphagia is longer lasting when CSD is instituted 3 weeks later. They conclude that recovery of feeding involves the "consolidation of reorganized neural connections." Finally, recovery of feeding may involve pre- and postlesion experience with food. Di Cara (1970) shows that rats which had never ingested milk preoperatively did not recover feeding without postoperative feeding experience, but rats which had been fed milk preoperatively recovered feeding spontaneously without postoperative experience. Thus, rats with LH lesions may avoid novel foods to a greater extent than rats without lesions.

This research was supported by a National Research Council of Canada grant to Nelson L. Freedman. We thank M. E. Olds for critical reading of the manuscript and $\mathrm{L}$. Baxter for running the animals and data analysis. R.W. is currently at Department of Psychology, Université de Québec à Trois Rivières, Québec.
Paradoxically, even without LH lesions, cortical interference by ablation or CSD can produce effects on feeding which are remarkably similar to the lateral hypothalamic syndrome. Braun (1966) and Horel, Bettinger, Royce, and Meyer (1969) pointed out the similarity between recovery of feeding following anterior cortical ablation and following LH lesions. Glick and Greenstein (1973) show that similar to the LH syndrome, aphagia following frontal cortical aspiration can also be modulated by preoperative feeding experience. Moreover, CSD directly affects ingestion of glucose in otherwise intact rats (Freedman et al., 1972). Within 16-20 min after CSD, rats terminate glucose intake and do not fully recover $24 \mathrm{~h}$ later. Thus, the previously reported apparent reinstatement of lateral hypothalamic aphagia to cortical interference may in fact represent neocortical aphagia. Moreover, since the reinstated aphagia typically involves novel, highly palatable foods and outlasts the SD by sometimes several days, there is a strong possibility that SD concurrently induces a conditioned aversion.

The usual demonstration of conditioned taste aversion involves exposure to a novel food (CS) followed at varying time intervals by a treatment (US) designed to induce gastrointestinal (GI) distress. Long-lasting taste aversion has been produced with such diverse USs as X-irradiation (Garcia, Kimeldorf, \& Hunt, 1961), cyclophosphamide (Peck \& Ader, 1974), apomorphine, lithium chloride, and emetine (e.g., Revusky \& Gorry, 1973). The common feature of all these treatments is that they produce nausea, anorexia, lethargy, or general malaise associated with GI distress. The demonstration that cortical interference induced by CSD also produces a onetrial conditioned aversion to novel foods would add an important new dimension to taste aversion theory. The present experiment examines these notions in detail. 


\section{METHOD}

\section{Subjects and Surgery}

Thirty-two male hooded rats, obtained from Canadian Breeding Laboratories, weighed an average $230 \mathrm{~g}$ at the beginning of the experiment. Rats were anesthetized intraperitoneally for surgical preparation with sodium pentobarbital (Nembutal, $65 \mathrm{mg} / \mathrm{kg}$ ). Polyethylene cannulae which permitted direct chemical access to the dura were then firmly affixed bilaterally to the skull with dental cement (Lang's cold-cure acrylic) and stainless steel screws $(00-80 \times 1 / 8$ in. $)$. In this preparation, $25 \%$ potassium chloride $(\mathrm{KCl})$ for spreading cortical depression (CSD) or mammalian Ringer's containing $0.9 \% \mathrm{NaCl}$ for a neutral isotonic control solution could be introduced into the cortical cannulae immediately following exposure to novel foods. This treatment, using the same preparation, has been shown to produce both physiological and behavioral CSD (Freedman \& Bureš, 1972). The cannulae were sealed with cotton pellets soaked in Ringer's to prevent drying of exposed tissue. The rats were then replaced in their cages to recover for $48 \mathrm{~h}$. This recovery time was sufficient for most rats to eat and drink typical presurgical amounts.

\section{Procedure}

Following surgical recovery, the rats were first water-deprived for $24 \mathrm{~h}$ to ensure subsequent drinking. Half the rats were then given $1 \mathrm{~h}$ access to a novel $0.3 \%$ sodium saccharin solution, and the other half, $1 \mathrm{~h}$ access to ordinary tap water. Immediately after this exposure, half of the rats in each group received approximately $0.05 \mathrm{ml}$ of $25 \% \mathrm{KCl}$ in the dural cannulae to generate bilateral CSD. The other half served as control rats and received an equal volume of mammalian Ringer's in the cannulae. Following a single 1-h exposure to these treatments, the cannulae for all groups were rinsed with Ringer's and reclosed with cotton pellets. Subsequent intake of $0.3 \%$ sodium saccharin solution and tap water was monitored every $12 \mathrm{~h}$ for 6 days from two identical 100-ml Richter tubes mounted on the home cages. To avoid position preferences, the position of the Richter tubes containing saccharin and tap water was reversed after each 12 -h reading. The data were converted to proportion of total daily fluid intake taken as saccharin solution. Thus, if a rat drank equal volumes of saccharin and water, the proportion was 0.50 ; if a greater volume of saccharin was ingested, the proportion was between 0.50 and 1.00 , and if less saccharin than water was ingested, the proportion fell between 0.00 and 0.50 . Daily weights of Lab Chow were also monitored to determine whether effects generalized to foods other than those specifically trained. Spillage was not taken into account since there was no reason to believe this would be differentially affected by the treatments.

\section{RESULTS}

Eventually every animal took $100 \%$ of its 12 -h posttreatment fluid intake as saccharin solution. Thus, the saccharin became a highly preferred fluid. Therefore, to assess whether the treatments were differentially aversive, the amount of time following treatment to attain criteria of both $75 \%$ and $100 \%$ saccharin intake in a 12 -h period was determined. The two criteria were used to ensure that the results were not specific to a very stringent or a very permissive criterion. In both cases, the more aversive the treatment, the greater should be the time to attain the criterion.

Table 1 shows the mean number of 12 -h periods to the $75 \%$ or $100 \%$ criterion for each of the treatment groups. For Ringer's and $\mathrm{KCl}$ groups combined, a significantly greater time to both criterion measures
Table 1

Mean 12-h Periods to $75 \%$ or $100 \%$ Recovery of Saccharin Intake

\begin{tabular}{llllll}
\hline & \multicolumn{4}{c}{ Chemical on Dura } \\
\cline { 2 - 3 } \multicolumn{1}{c}{$\begin{array}{c}\text { Pretreatment } \\
\text { Exposure }\end{array}$} & $75 \%$ & $100 \%$ & & $75 \%$ & $100 \%$ \\
\cline { 2 - 3 } \cline { 5 - 6 } & & \multicolumn{2}{c}{ Ringer's } & & \multicolumn{2}{c}{$\mathrm{KCl}$} \\
\hline $\begin{array}{l}\text { Distilled Water } \\
\text { 3\% Sodium Saccharin }\end{array}$ & 4.12 & 3.88 & & 3.38 & 5.12 \\
\hline
\end{tabular}

${ }^{*} p<.005$ compared to respective Ringer's control

occurred for preexposure to saccharin than to water $\left(\mathrm{F}_{75 \%}=11.34, \mathrm{df}=1 / 28, \mathrm{p}<.005 ; \mathrm{F}_{100 \%}=4.87\right.$, $\mathrm{df}=1 / 28, \mathrm{p}<.05)$. Thus, aversion to saccharin is greater for treatment which follows a novel saccharin solution than for the same treatment following familiar water, and confirms that the present procedures induced the "Garcia effect" (Garcia \& Erwin, 1968).

In contrast to the normal preference for the novel saccharin solution, rats depressed with $25 \% \mathrm{KCl}$ preferred water to saccharin for at least $24 \mathrm{~h}$ and some preferred water for up to 6 days following treatment. This aversion is reflected by the fact that averaged across both pretreatment fluids, $\mathrm{KCl}$ depressed rats averaged $64.56 \mathrm{~h}$ to recover $75 \%$ saccharin intake and $78.72 \mathrm{~h}$ to recover $100 \%$ saccharin intake, while the Ringer's control rats required only $43.56 \mathrm{~h}$ to $75 \%$ recovery and $52.56 \mathrm{~h}$ to $100 \%$ recovery $\left(\mathrm{F}_{75 \%}=5.56, \mathrm{df}=1 / 28, \mathrm{p}<.05\right.$; $\left.\mathrm{F}_{100 \%}=6.21, \mathrm{df}=1 / 28, \mathrm{p}<.025\right)$. Inspection of Table 1 shows that this spreading depressioninduced aversion occurs only with novel saccharin preexposure but not with the more familiar water. Orthogonal comparisons confirmed that animals preexposed to saccharin followed by treatment with $\mathrm{KCl}$ took significantly greater time to recover $75 \%$ or $100 \%$ saccharin intake compared to all other groups combined $\left(\mathrm{F}_{75 \%}=14.33, \mathrm{df}=1 / 28, \mathrm{p}<.005\right.$; $\mathrm{F}_{100 \%}=11.11$, df $\left.=1 / 28, \mathrm{p}<.005\right)$. No other comparisons were significant.

Figure 1 shows the proportion of total fluid intake per 12-h period taken as saccharin. The groups preexposed to water show relatively little initial aversion and take more than $50 \%$ of their intake as saccharin even in the first $12 \mathrm{~h}$. These animals attained $100 \%$ saccharin intake by the end of $48 \mathrm{~h}$. Likewise, the group preexposed to saccharin followed by treatment with Ringer's shows about the same pattern. Only the group preexposed to saccharin followed by a single $\mathrm{KCl}$ treatment shows an immediate and long-lasting aversion to saccharin. These impressions are confirmed by a significant Sessions effect $(F=6.82$, $\mathrm{df}=11 / 308, \mathrm{p}<.001)$. Orthogonal comparisons on the Treatment by Sessions interaction further showed that the group preexposed to saccharin and then treated with $\mathrm{KCl}$ showed significantly lower saccharin preference than the other three groups combined 


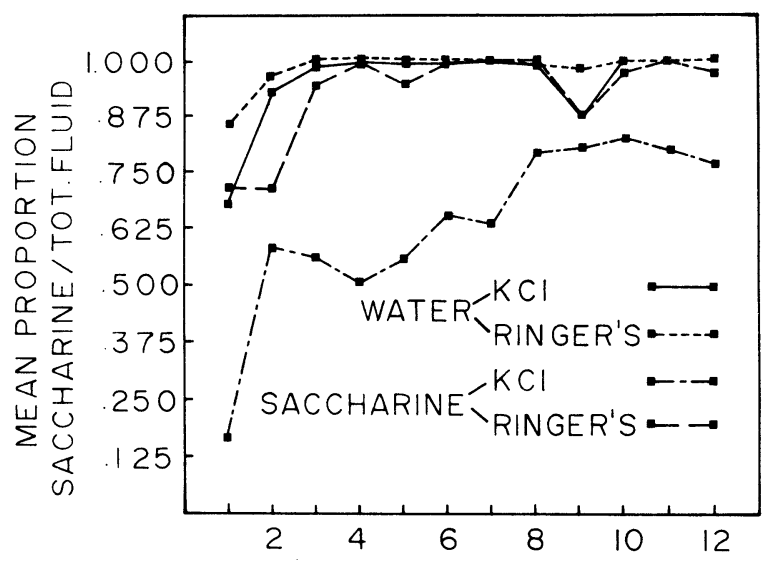

12-HR. INTERVALS POST-TREATMENT

Figure 1. The effects of preexposure to water or saccharin followed by $\mathrm{KCl}$-induced spreading depression or Ringer's control treatment on subsequent 12-h saccharin intake expressed as a proportion of total fluid intake in the same period.

across Sessions $(F=168.73, \mathrm{df}=1 / 308, \mathrm{p}<.001)$. No other comparison was significant.

Rats treated with $\mathrm{KCl}$ tended to use small, but reliably greater, amounts of Lab Chow on subsequent days than the Ringer's treated counterparts $(\mathrm{F}=8.49, \mathrm{df}=1 / 28, \mathrm{p}<.01)$. This may represent a small rebound effect after recovery from CSD. However, the largest difference between groups was only $4.37 \mathrm{~g}$ and was within the margin of error produced by spillage (Table 2). There was no consistent tendency for one group to eat more than any other across days. Table 2 confirms that CSD definitely did not produce a general debilitation in eating, nor did it produce a generalized aversion to familiar food in the form of Lab Chow since in both cases $\mathrm{KCl}$-treated rats ate (and/or spilled) more food than did Ringer's controls.

\section{DISCUSSION}

We shall argue that (a) cortical spreading depression (CSD) produces a long-lasting conditioned aversion to novel food that is unrelated to general debilitative effects or to memory impairment, (b) that this aversion represents a CNS concommitant of GI distress similar to the CNS mechanism proposed for learned aversion, and (c) finally, the reinstatement of lateral hypothalamic aphagia by cortical interference is jointly a function of neocortical and hypothalamic

Table 2

Mean Daily Use of Lab Chow in Grams in the $24 \mathrm{~h}$ Following $\mathrm{KCl}$ and Ringer's Treatment

\begin{tabular}{lccc}
\hline \multirow{2}{*}{$\begin{array}{c}\text { Pretreatment } \\
\text { Exposure }\end{array}$} & \multicolumn{2}{c}{ Chemical on Dura } & \\
\cline { 2 - 3 } & Ringer's & $\mathrm{KCl}$ & Difference \\
\hline Distilled Water & 36.39 & 37.48 & 1.09 \\
.3\% Sodium Saccharin & 35.25 & 39.62 & 4.37 \\
Mean & 35.82 & 38.55 & 2.73 \\
\hline
\end{tabular}

de-encephalization and aversion of the novel feeding procedures used during recovery conditioned to the CSD.

The present results indicate that functional neocortical interference induced by CSD produces a long-lasting aversion to saccharin solution. This aversion cannot be attributed to a general debilitative effect of CSD, for several reasons. First, rats exposed to water followed by CSD treatment do not show subsequent saccharin aversion, but rats exposed to saccharin and then CSD do. Second, the putative general debilitation following CSD should reduce both water and saccharin intake equally but would not be expected to differentially alter the proportionate intake of the two solutions. In fact, in the present study, proportionate intake following CSD was completely reversed, from saccharin preference to water preference relative to the other control groups. Finally, general debilitative effects on days following CSD treatments were not seen in normal feeding patterns reflected by daily amounts of Lab Chow used, which, if anything, was greater for rats that had formerly been depressed.

It might be argued that CSD impairs memory since it immediately follows the first experience with saccharin. If memory were impaired, subsequent selection of water and saccharin should be equally likely. However, the present data show that the CSD rats exposed to saccharin show an immediate distaste for that liquid and preferentially select water in the first $12 \mathrm{~h}$ following treatment and for some time afterward. The control rats not exposed to saccharin but also given CSD show an immediate preference for saccharin over water. Although for some types of conditioning CSD does impair memory, such impairment does not seem to be an important factor in this type of conditioning.

That CSD has aversive properties has been previously demonstrated in rats which avoid the place where they receive $\mathrm{KCl}$-induced CSD but show no such avoidance to Ringer's (Freedman \& Whitman, 1972). The demonstrated aversion in the present study to saccharin most likely represents one-trial conditioned aversion produced by these aversive properties. The controls used in the present study are appropriate to a Pavlovian conditioning paradigm. As expected, exposure to saccharin $\left(\mathrm{CS}^{+}\right)$ paired with behaviorally inactive Ringer's (UCS ${ }^{\circ}$ ) treatment does not lead to conditioned aversion. Likewise, the unpaired control of $\mathrm{KCl}$ alone (UCS ${ }^{+}$) does not produce saccharin aversion. Finally, there is no aversion produced by Ringer's (UCSo) alone. Only the explicit pairing of saccharin $\left(\mathrm{CS}^{+}\right)$and $\mathrm{KCl}$ $\left(\mathrm{UCS}^{+}\right)$in a single trial produces long-lasting conditioned aversion. Apparently, the noxious or aversive aftereffects of CSD become conditioned to the novel taste cues. This aversion is not easily distinguishable from that produced by GI distress and suggests a reinterpretation of taste-aversion theory. 
Rozin and Kalat have emphasized that in the natural state "tastes are causally linked to GI events and there is a long inherent delay between taste and it's consequences (1971, p. 470)." They postulate that learning with this long delay constitutes an adaptive, centrally mediated, mechanism. With this mechanism, the animal learns, as time passes without unfavorable GI consequences, that the novel food is safe. The present demonstration that CSD produces conditioned aversion without apparent GI distress suggests that other possible forms of distress may be sufficient to produce aversion. However, noxious USs not specifically related to GI distress, such as footshock, do not produce taste aversion (Garcia \& Koelling, 1966). Another possibility is that the reversible temporary lesion produced by CSD impairs the central mechanism through which novel tastes are associated with favorable consequences. However, lesions of the cortex by aspiration normally produce deficits in learned aversion (Hankins, Garcia, \& Rusiniak, 1974), while the present study clearly shows the opposite. There remains the possibility that CSD produces learned aversion by mimicking some of the CNS consequences of GI distress. Thus, CSD may actually be tapping into a "cognitive" component of GI distress which is the central mechanism mediating long delay in learned aversion.

The bulk of lesion, CSD, and neurochemical evidence points rather consistently to the involvement of neocortex in the encephalization of hunger (Teitelbaum, 1971). The exact nature of this involvement leads to several questions. First, is the reinstatement of aphagia produced by CSD (Teitelbaum \& Cytawa, 1965) solely a result of neocortical aphagia? If such were the case, aphagia should last as long as the cortex is rendered nonfunctional. In fact, Teitelbaum and Cytawa show that the reinstated aphagia consistently outlasts CSD by several days. Why, then, is the reinstated aphagia in recovered LH animals so persistent? One possibility is that the animal must relearn habits associated with eating following $\mathrm{LH}$ lesions and that this learning depends on cortical integrity. Because CSD more effectively reinstates aphagia when given soon after recovery from LH lesions rather than later suggests that some relearning and consolidation must occur (Balinska et al., 1967). A second possibility is that the CSD produces a learned aversion to novel foods and maintainence procedures instituted during the reencephalization process after $\mathrm{LH}$ lesions. One prominent feature of taste aversion is the slow decay of the delay-of-reinforcement gradient (Rozin \& Kalat, 1971). The differences between the above studies may be due to CSD being initiated at different times after recovery. CSD initiated long after recovery (long CS-US delay) produces only a brief reinstatement of aphagia which probably represents the joint effects of neocortical aphagia and lateral hypo- thalamic aphagia. CSD initiated shortly after recovery from aphagia (short CS-US delay) produces a long-lasting reinstatement of aphagia which most likely represents the joint effects of neocortical and hypothalamic aphagia and conditioned aversion to novel taste stimuli preceding CSD, as demonstrated in the present study.

\section{REFERENCES}

Balinská, H., Buresová, O., \& Fifková, E. The influence of cortical and thalamic spreading depression on feeding behavior of rats with lateral hypothalamic lesions. Acta Biologiae Experientia (Warsaw), 1967, 27, 355-363.

Braun, J. J. The neocortex and visual placing in rats. Brain Research, 1966, 1, 381-394.

Di CARA, V. Role of post-operative feeding experience in recovery from lateral hypothalamic damage. Journal of Comparative and Physiological Psychology, 1970, 72, 60-65.

Freedman, N. L., \& Bureś, J. Conditions of phasic impairment of avoidance responding during bilateral spreading depression. Journal of Comparative and Physiological Psychology, 1972, 78, 433-441.

Freedman, N. L., Ferguson, D., \& Wilson, D. Regulatory and non-regulatory effects of functional decortication on eating in rats. Journal of Comparative Physiological Psychology, 1972, 81, 232-242.

Freedman, N. L., \& Whitman, R. D. Aversiveness of functional decortication and performance deficit. T. -I.-T. Journal of Life Sciences, 1972, 2, 73-79.

Garcia, J., \& ERwin, F. Gustatory-visceral and teloreceptorcutaneous conditioning: Adaptation in internal and external milieus. Communications in Behavioral Biology, 1968, Part A, 1, 389-415.

Garcia, J., Kimeldorf, D., \& Hunt, E. The use of ionizing radiation as a motivating stimulus. Psychological Review, 1961, 68, 383-385.

Garcia, J., \& Koelling, R. Relation of cue to consequences in avoidance learning. Psychonomic Science, 1966, 4, 123-124.

Glick, S., \& Greenstein, S. Recovery of weight regulation following ablation of frontal cortex in rats. Physiology and Behavior, 1973, 10, 491-496.

Hankins, W., Garcia, J., \& Rusiniak, K. Cortical lesions: Flavor illness and noise shock conditioning. Behavioral Biology, 1974, 10, 173-181.

Horel, J., Bettinger, L., Royce, G., \& Meyer, D. R. Role of the neocortex in the learning and relearning of visual habits by the rat. Journal of Comparative and Physiological Psychology, 1969, 67, 430-441.

PeCK, J. H., \& ADER, R. Illness induced taste-aversion under states of deprivation and satiation. Animal Learning \& Behavior, 1974, 2, 68 .

REVUSKY, S., \& GoRRY, T. Flavor aversions produced by contingent drug injection: Relative effectiveness of apomorphine, emetine and lithium. Behavior Research and Therapy, 1973, 11, 403-409.

Rozin, P., \& Kalat, J. Specific hungers and poison avoidance as adaptive specializations of learning. Psychological Review, 1971, 78, 459-486.

Teitelbaum, P. The encephalization of hunger. In E. Stellar \& J. M. Sprague (Eds.), Progress in physiological psychology (Vol. 4). New York: Academic Press, 1971.

Teitelbaum, P., Cheng, M., \& Rozin, P. The development of feeding parallels its recovery after hypothalamic damage. Journal of Comparative and Physiological Psychology, 1969, 67, 430-441.

Teitelbaum, P., \& Cytawa, J. Spreading depression and recovery from lateral hypothalamic damage. Science, 1965, 147, 61-63.

(Received for publication April 29, 1976; revision accepted August 26, 1976.) 